\title{
Targets for adapting intravenous iron dose in hemodialysis: a proof of concept study
}

\author{
N. O. Peters ${ }^{1 *}$, N. Jay ${ }^{2,3}$, J. Cridlig ${ }^{1}$, G. Rostoker ${ }^{4}$ and L. Frimat ${ }^{1}$
}

\begin{abstract}
Background: Intravenous iron is widely used to control anemia in dialysis patients and limits costs related to erythropoiesis-stimulating agents (ESA). Current guidelines do not clearly set upper limits for serum ferritin (SF) and transferrin saturation (TSAT). International surveys such as the Dialysis Outcomes and Practice Patterns Study (DOPPS) showed that this lack of upper limits potentially led nephrologists to prescribe iron infusions even for patients with a high SF. Recent publications have suggested a risk of short- and long-term adverse effects related to iron overload. We conducted a proof of concept study to assess the impact of reducing intravenous iron administration.

Methods: In a prospective 8-month study conducted in a hospital dialysis unit, we assessed the impact of a strategy designed to reduce iron infusions. Instead of the usual strategy targeting 30-50\% TSAT irrespective of SF, intravenous iron was administered if and only if TSAT was below $20 \%$ and SF below $200 \mu \mathrm{g} / \mathrm{L}$. Routine practices for ESA remained unchanged: hemoglobin target 10-12 g/dL; ESA delivered monthly and dose corrected by $25 \%$ as necessary; ESA discontinued temporarily if hemoglobin $>13 \mathrm{~g} / \mathrm{dL}$; methoxy polyethylene glycol-epoetin beta generally used. Tests were ordered monthly to monitor hemoglobin. Intravenous iron was administered weekly and ESA monthly. Baseline and 6-month TSAT, SF and hemoglobin levels were compared.

Results: Six-month data were available for 45 patients (31 M/14 F; $67.6 \pm 14.0$ y; $53.9 \pm 85.7$ months on dialysis). Patients experienced the following comorbidities: ischemic heart disease $(n=29,44 \%)$, diabetes mellitus $(n=14 ; 31 \%)$, malignant disease $(n=11 ; 24 \%)$, transplantation $(n=11 ; 24 \%)$ and severe heart failure $(n=6 ; 13 \%)$. The mean weekly dose of iron declined from $77.8 \pm 87.6$ to $24.4 \pm 52.9 \mathrm{mg}$ per patient $(p=0.0003)$. SF decreased from $947.7 \pm 1056.4$ to $570.7 \pm 424$. $4 \mu \mathrm{g} / \mathrm{L}(p=0.0001)$, and TSAT from $41.5 \pm 22.4$ to $32.6 \pm 13.7 \%(p=0.01)$. Hemoglobin levels remained stable $(11.13 \pm 1.05$ vs. $11.00 \pm 1.16 \mathrm{~g} / \mathrm{dL}, p=0.54)$ as did ESA dose (126.4 \pm 91.9 vs. $108.2 \pm 112.7 \mu \mathrm{g} / 28$ days, $p=0.07)$.

Conclusions: Our study suggests that a regular hemoglobin level can be maintained using regular ESA doses combined with intravenous iron doses adapted to TSAT and SF thresholds lower than those used in routine practice. This strategy reduces the risk of iron overload.
\end{abstract}

Keywords: Intravenous iron, Chronic kidney disease, Dialysis, Anemia

\section{Background}

Although optimal therapeutic management of anemia in hemodialysis patients is still debated, there is a consensus on avoiding blood transfusions. Treatment of anemia was demonstrated to be correlated with an improvement in the quality of life and a reduction in morbi-mortality [1-4]. Some studies, however, highlighted a potential for harm from an overtreatment of anemia by showing that

\footnotetext{
* Correspondence: n.peters@chru-nancy.fr

'Department of Nephrology, University hospital, Vandoeuvre les Nancy, France

Full list of author information is available at the end of the article
}

too high target hemoglobin levels were associated with an increased cardiovascular risk $[5,6]$.

Recommendations for the use of iron and erythropoiesisstimulating agent (ESA) infusions are not unanimous [7-15]. The choice of biomarkers to monitor iron supplementation, as well as the target levels remains a matter for debate (Table 1). The use of intravenous (IV) iron in dialysis patient has increased substantially since the early 2000 s [16-19]. This increase was based on results from clinical studies showing a greater ESAs responsiveness in patients receiving iron supplementation [20-23]. The financial 
Table 1 Clinical practice guidelines for anemia management in chronic kidney disease according to transferring saturation, serum ferritin and upper limit of serum ferritin for iron supplementation

\begin{tabular}{lllll}
\hline Guidelines & & TSAT(\%) & Serum ferritin $(\mu \mathrm{g} / \mathrm{L})$ & Upper limit of serum ferritin $(\mu \mathrm{g} / \mathrm{L})$ \\
\hline KDOQ 2006 [16] & & $<20$ & $<100$ & 500 \\
CSN 2008 [18] & HD & $<20$ & $<200$ & None \\
& PD/ND & $<20$ & $<100$ & None \\
JSDT 2008 [11] & $<20$ & $<100$ & 500 \\
ERBP 2009 [17] & $<20$ & $<100$ & 500 \\
KDIGO 2012 [7] & & $<30$ & $<500$ & 500 (or TSAT > 30\%) \\
CSN 2012 [10] & & $<30$ & $<500$ & None \\
ERBP 2013 [8] & No ESA/no anemia & $<20$ & $<100$ & 500 \\
& No ESA/anemia/ND & $<25$ & $<200$ & 500 \\
& No ESA/anemia/HD or PD & $<25$ & $<300$ & 500 \\
KDOQI 2013 [9] & ESA/anemia/on dialysis & $<30$ & $<300$ & 500 \\
NICE 2015 [12] & & $<30$ & $<500$ & None \\
\hline
\end{tabular}

KDOQI Kidney Disease Outcomes Quality Initiative, CSN Canadian Society of Nephrology, JSDT Japanese Society of Dialysis Therapy, KDIGO Kidney Disease Improving Global Outcomes, ERBP European Renal Best Practice, NICE National Institute for Health and Care Excellence, HD on hemodialysis, PD peritoneal dialysis, $N D$ not on dialysis, ESA erythropoiesis-stimulating agent, TSAT transferrin saturation

criterion has remained, up until recently, a determinant for IV iron prescribing as shown by escalating trends in its utilization following changes in financial contribution to the treatment of anemia decided by the American Health System in the early 2010s [17]. In addition to its effectiveness for treating anemia, other benefits of IV iron supplementation, particularly cardiovascular, may have contributed to the rise of its prescribing [24-26]. In this context, the lack of an agreement about the level of an upper limit for serum ferritin in international guidelines may be partly responsible for the acceptance of some very high values for serum ferritin by nephrologists.

Since 2000, several studies have raised concerns about a long-term iron supplementation with supra-physiological doses in renal insufficiency. Thus mortality rate was shown to be correlated with iron dose in the Dialysis Outcomes and Practice Patterns Study (DOPPS) [27]. Several prospective studies demonstrated potential adverse effects due to prolonged use of high dose IV iron [4, 28-32]. Liver iron overload was demonstrated in almost all hemodialysis patients receiving IV iron using magnetic resonance imaging techniques [33, 34]. In addition, several cases of anaphylaxis associated with IV iron infusions were reported $[35,36]$. Although it is very difficult to ascertain the frequency of these severe reactions associated with IV iron, it was estimated at one reaction for every five million doses from US data [35]. In addition, three deaths per year were ascribed to intravenous iron infusions in US death certificate data [35].

As a result, the use of IV iron was regulated by the French and European Health Authorities [37, 38]. Taking into account of these recent data, experts have become more cautious about iron supplementation in dialysis [39-41].

In this context, we expressed a desire to change our IV iron supplementation practices by switching from widely prescribing that was presumed to be safe until now to responsible prescribing. Thus we have restricted IV iron supplementation to patients with both serum ferritin levels under $200 \mu \mathrm{g} / \mathrm{L}$ and transferrin saturation (TSAT) under $20 \%$. The change in our IV iron supplementation practices for the management of iron deficiency in hemodialysis patients has been systematically implemented in our dialysis unit since February 2014.

\section{Methods}

\section{Study design}

We conducted a prospective 8-month study to assess the efficacy and the safety of this approach that was more restrictive in iron supplementation for the management of anemia among all patients undergoing dialysis in our hospital dialysis unit.

Enrolled patients were all adults who had been on dialysis for at least 3 months in our unit. During dialysis sessions, they were given anticoagulant as an initial single bolus of enoxaparine or a continuous infusion of heparin sodium. Routine practices for ESA remained unchanged: hemoglobin target levels were 10-12 g/dL; ESA was delivered monthly and its dose could be adjusted by $25 \%$ as necessary; ESA was discontinued temporarily if hemoglobin was above $13 \mathrm{~g} / \mathrm{dL}$; methoxy polyethylene glycol-epoetin beta was mainly used.

Biochemical parameters for iron status and for the assessment of anemia had been followed in all patients 
undergoing dialysis in our unit between February and September, 2014.

\section{Data collection}

At the beginning of the follow-up, we collected medical history, treatment and the main biochemical parameters for all patients. We checked comorbidities associated with chronic kidney disease (CKD), such as diabetes, ischemic cardiopathy, cancer, malignant blood disease, and digestive disease, as well as treatment, particularly anticoagulant and antiplatelet agents.

Regarding dialysis sessions, we reported the following parameters: treatment options for renal replacement therapy, such as hemodialysis or hemodiafiltration, weekly duration of dialysis sessions, and ESA dose.

The following biochemical parameters were assessed every 28 days: hemoglobin, TSAT, serum ferritin, serum calcium, serum phosphorus, serum $\beta 2$-microglobuline, serum albumin and C-reactive protein (CRP). Parathyroid hormone $(\mathrm{PTH})$ level was assessed within the first weeks after the beginning of the study and at the end of the follow-up period. The following patient outcomes had been reported throughout the follow-up: death, transplantation, presence in our dialysis unit after a 6month follow-up and transfer to another dialysis unit, as well as hospitalizations and reasons of admissions.

\section{Regimens of IV iron supplementation}

At the beginning of the study, the target dose-regimen for IV iron supplementation aimed to maintain TSAT between 30 and 50\%, irrespective of serum ferritin levels, in ESA-treated patients in order to avoid iron deficiency anemia. In ESA-naive patients, IV iron supplementation was given in those with hemoglobin level under $12 \mathrm{~g} / \mathrm{dL}$ or iron deficiency (serum ferritin $<200 \mu \mathrm{g} / \mathrm{L}$ and TSAT $<20 \%$ ).

Our new therapeutic strategy for iron deficiency therapy aimed to prescribe IV iron supplementation only in anemic patients with TSAT $<20 \%$ and serum ferritin $<200 \mu \mathrm{g} / \mathrm{L}$, simultaneously. The weekly iron dose was 100 or $200 \mathrm{mg}$ in patients requiring iron supplementation.

In our unit, iron is administered intravenously as a weekly single dose during the midweek dialysis session in patients on hemodialysis three times per week. Our source of iron is ferric hydroxide sucrose complex.

\section{Assessment criteria}

The main assessment criterion was the change in hemoglobin levels after adaptation of IV iron therapy in patients with a 6-month follow-up in our unit.

The secondary criteria were the change in TSAT, serum ferritin levels and ESA dose after a 6-month follow-up period.

\section{Statistical analysis}

Comorbidities in patients at inclusion, as well as characteristics of treatment and dialysis sessions are expressed in \% of patients. Biochemical parameters, iron doses and ESA doses are described by mean and standard deviation. Student's t-test and McNemar's test were used to compare change of biochemical parameters and of IV iron prescription during the study, respectively.

\section{Results}

Among the 55 patients undergoing dialysis in our unit at the beginning of the study, 45 had been followed up throughout the study as shown in Fig. 1.

\section{Patient characteristics}

Sample characteristics are detailed in Table 2. Our population study consisted mainly of men (68.9\%). The mean age was $67.6 \pm 14.0$ years. The mean duration of renal replacement therapy was $53.9 \pm 85.7$ months. The most common cause of end-stage renal failure was hypertensive nephropathy. Ischemic heart disease and diabetes were the most concomitant pathologies. The majority of patients were given antiplatelet agents.

Anticoagulation with low molecular weight heparin (LMWH) during dialysis sessions was used in all patients. The mean duration of dialysis session was $13.1 \pm$

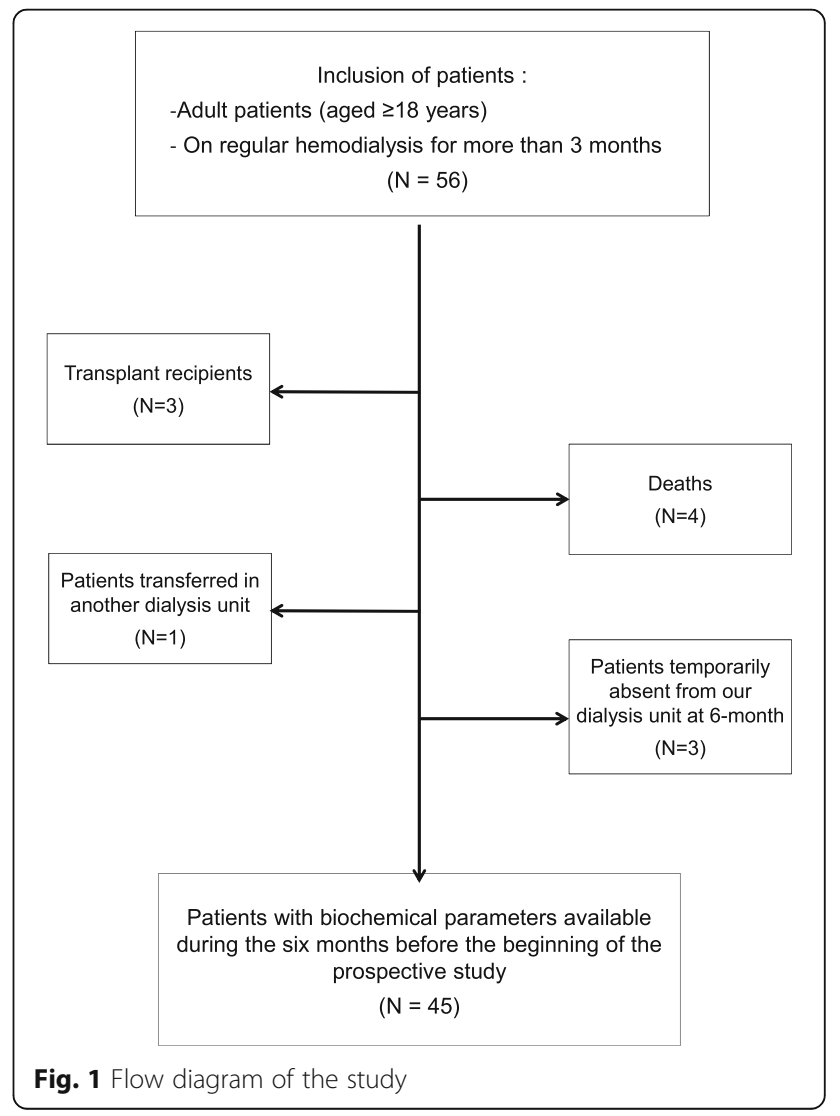


Table 2 Clinical characteristics of sample at inclusion $(N=45)$

\begin{tabular}{|c|c|}
\hline Characteristics & \\
\hline \multicolumn{2}{|l|}{ Gender, N (\%) } \\
\hline Male & $31(68.9 \%)$ \\
\hline Age (years) & $67,58 \pm 14,02$ \\
\hline \multicolumn{2}{|c|}{ History of chronic kidney disease, N (\%) } \\
\hline Hypertensive nephropathy & $21(46.7 \%)$ \\
\hline Glomerular nephropathy & $7(15.6 \%)$ \\
\hline Uropathy & $5(11.1 \%)$ \\
\hline Diabetes & $4(8.9 \%)$ \\
\hline Others & $8(17.8 \%)$ \\
\hline \multicolumn{2}{|l|}{ Antecedents, N (\%) } \\
\hline Transplantation & $11(24.4 \%)$ \\
\hline Diabetes & $14(31.1 \%)$ \\
\hline Malignant disease & $11(24.4 \%)$ \\
\hline Infection & $11(24.4 \%)$ \\
\hline Hemorrhage & $12(26.7 \%)$ \\
\hline Heart disease & $29(64.4 \%)$ \\
\hline Ischemic heart disease & $20(44.4 \%)$ \\
\hline Heart failure & $6(13.3 \%)$ \\
\hline Previous time of dialysis (months) & $53,97 \pm 86,26$ \\
\hline \multicolumn{2}{|l|}{ Type of dialysis, n (\%) } \\
\hline Hemodialysis & $32(71 \%)$ \\
\hline Hemodiafiltration & $13(29 \%)$ \\
\hline \multicolumn{2}{|l|}{ Vascular access, $\mathrm{N}(\%)$} \\
\hline Arteriovenous fistula & $37(82.2 \%)$ \\
\hline Arteriovenous graft & $3(6.7 \%)$ \\
\hline Venous catheter & $5(11.1 \%)$ \\
\hline \multicolumn{2}{|l|}{ Treatment, N (\%) } \\
\hline Anticoagulants & $7(15.6 \%)$ \\
\hline Antiplatelet agents & $32(71.1 \%)$ \\
\hline
\end{tabular}

$1.7 \mathrm{~h}$ per week. Patients were undergoing hemodialysis (68.9\%) and hemodiafiltration (31.1\%).

\section{Patients' outcomes}

Patients were followed up during 22.5 patient-years.

Reported reasons for lost to follow-up (transplantation, death, center change or unavailable data) are detailed in Fig. 1. The causes of deaths were attributed to cardiovascular diseases $(N=3)$ and infection $(N=1)$. Temporary absences from our unit were due to transient dialysis in other centers for medical reasons or holidays.

A total of 27 hospital admissions have been recorded during the follow-up, i.e. a hospitalization rate of 1.2 patient-years. Infections were responsible for one out of four admissions.

\section{Biochemical parameters}

Hemoglobin levels remained stable throughout the follow-up $(p=0.54)$ (Fig. 2a). An expected significant decrease, by contrast, was observed for biochemical markers of iron status, such as serum ferritin ( $p=$ $0.0001)$ and TSAT $(p=0.01)$ (Fig. $2 \mathrm{~b}$ and c). During the same period, the number of patients with iron deficiency anemia remained stable; the number of patients with TSAT values under $20 \%$ decreased from 8 to 7 ; the number of patients experiencing serum ferritin levels under $200 \mu \mathrm{g} / \mathrm{L}$ quadrupled, without any patient with serum ferritin levels under $100 \mu \mathrm{g} / \mathrm{L}$. PTH and CRP levels remained stable throughout the follow-up. $\beta 2$ microglobuline significantly decreased $(p=0.00001)$ and serum albumin levels significantly increased $(p=0.0002)$, as shown in Table 3.

\section{Management of anemia}

At the beginning of the study, patients were given a mean weekly iron dose of $77.8 \pm 87.6 \mathrm{mg}$ - i.e. IV iron infusion of $310 \mathrm{mg}$ per month. Among the 45 patients with a follow-up, 25 patients were given IV iron infusion during dialysis sessions; the mean weekly iron dose of iron was $140.0 \pm 70.1 \mathrm{mg}$ - i.e. IV iron infusion of $560 \mathrm{mg}$ per month.

After a 6-month period, the mean weekly iron dose was significantly reduced to $24.4 \pm 52.9 \mathrm{mg}(p=0.0003)$ - i.e. IV iron infusion of $97.6 \mathrm{mg}$ per month (Fig. 3). Only nine patients out of the 45 patients were treated with a mean weekly iron dose of $122.2 \pm 44.1 \mathrm{mg}$ - i.e. IV iron infusion of $488 \mathrm{mg}$ per month. In addition, the number of patients receiving IV iron infusion was significantly reduced from 50 to $20 \%(p=0.001)$.

At the beginning of the follow-up the mean ESA dose was $126.4 \pm 91.9 \mu \mathrm{g} /$ patient $/ 28$ days $(N=45)$; 42 patients were treated and were given a mean ESA dose of 135.4 $\pm 88.4 \mu \mathrm{g} /$ patient $/ 28$ days, while 3 patients did not receive ESA (Fig. 2d). At the end of the follow-up period, the mean ESA dose was $108.2 \pm 112.7 \mu \mathrm{g} /$ patient $/ 28$ days $(N=45) ; 36$ patients were treated and were given a mean ESA dose of $135.2 \pm 110.5 \mu \mathrm{g} /$ patient $/ 28$ days, while nine patients did not receive ESA. ESA dose remained stable during the follow-up $(p=0.07)$. All treatments of anemia are detailed in Table 3.

\section{Discussion}

The present study highlighted that lower targets for serum ferritin and TSAT enabled a reduction of iron supplementation without lowering hemoglobin levels or increasing ESA dose. The targets for serum ferritin and TSAT we used to adapt treatment were in accordance with the current international guidelines for the management of anemia [7, 8]. Biomarkers and targets recommended for anemia management have been regularly 

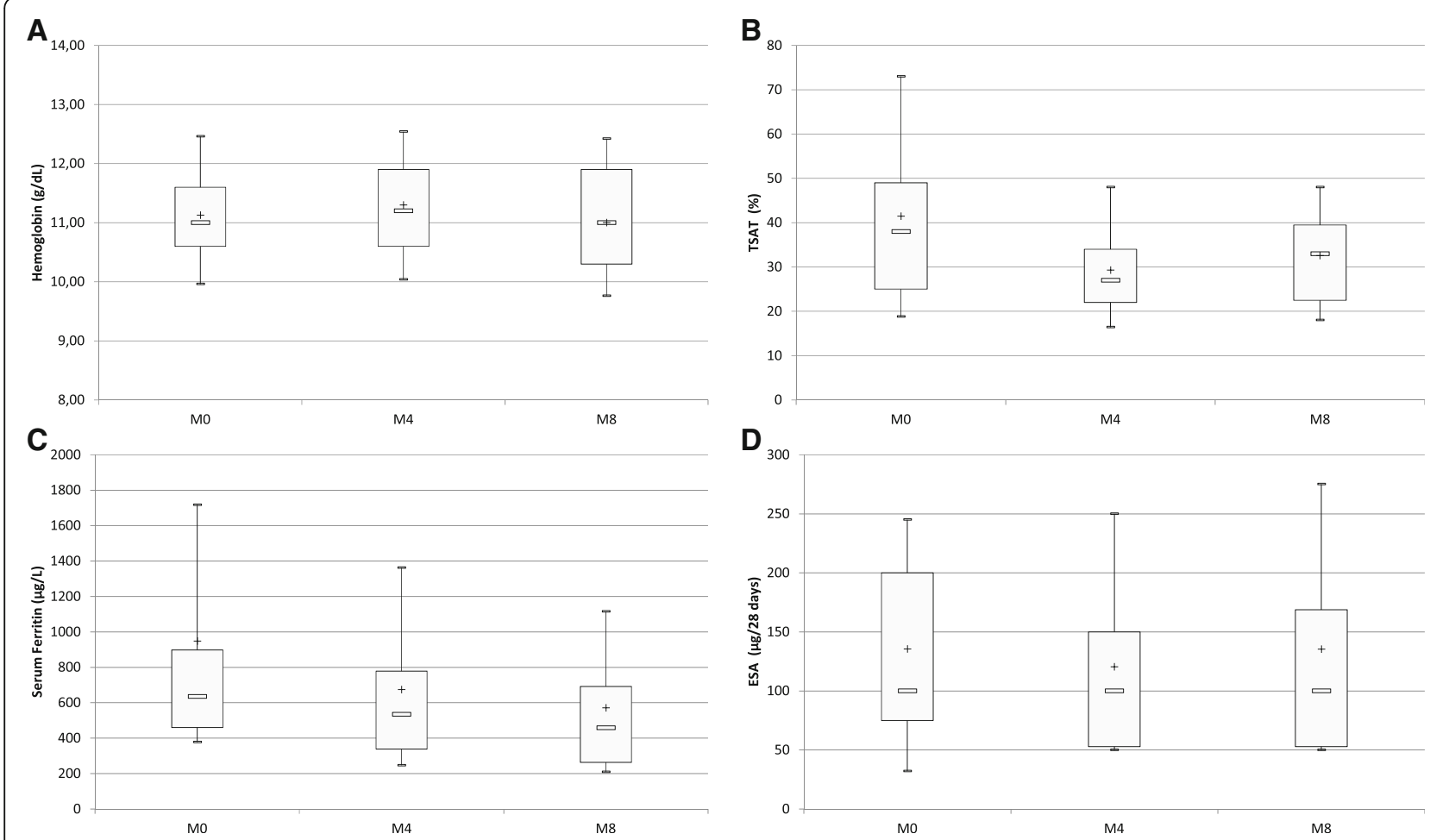

Fig. 2 Box-and-whisker plots of change in biochemical indicators of iron status and ESA doses during the follow-up period. a Box-and-whisker plots of change in hemoglobin levels during the follow-up period. Limits of boxes are $1^{\text {st }}$ quartile (lower limit) and $3^{\text {rd }}$ quartile (upper limit), with + and $\square$ being the mean and median values, respectively. Ends of whiskers indicate $1^{\text {st }}$ decile (lower end) and $9^{\text {th }}$ decile (upper end) $(p=0.54)$. $\mathbf{b}$ Box-and-whisker plots of change in TSAT during the follow-up. Limits of boxes are $1^{\text {st }}$ quartile (lower limit) and $3^{\text {rd }}$ quartile (upper limit), with + and $\square$ being the mean and median values, respectively. Ends of whiskers indicate $1^{\text {st }}$ decile (lower end) and $9^{\text {th }}$ decile (upper end) $(p=0.01)$. c Box-and-whisker plots of change in serum ferritin during the follow-up. Limits of boxes are $1^{\text {st }}$ quartile (lower limit) and $3^{\text {rd }}$ quartile (upper limit), with + and $\square$ being the mean and median values, respectively. Ends of whiskers indicate $1^{\text {st }}$ decile (lower end) and $9^{\text {th }}$ decile (upper end) $(p=0.0001)$. $\mathbf{d}$ Box-and-whisker plots of change in prescribed ESA doses during the follow-up. Limits of boxes are $1^{\text {st }}$ quartile (lower limit) and $3^{\text {rd }}$ quartile (upper limit), with + and $\square$ being the mean and median values, respectively. Ends of whiskers indicate $1^{\text {st }}$ decile (lower end) and $9^{\text {th }}$ decile (upper end) $(p=0.07$ )

Table 3 Comparisons of biochemical parameters and treatment for anemia during the 6-month follow-up

\begin{tabular}{|c|c|c|c|c|}
\hline & At inclusion (M0) & At month 3 & At month 6 & $P$ \\
\hline \multicolumn{5}{|l|}{ Biochemical parameters } \\
\hline Hemoglobin (g/dL) & $11.13 \pm 1.05$ & $11.30 \pm 1.09$ & $11.00 \pm 1.16$ & 0.54 \\
\hline TSAT (\%) & $41.47 \pm 22.37$ & $29.27 \pm 10.88$ & $32.58 \pm 13.63$ & 0.01 \\
\hline Serum ferritin $(\mu \mathrm{g} / \mathrm{L})$ & $947.71 \pm 1056.42$ & $672.93 \pm 490.16$ & $570.73 \pm 424.41$ & 0.0001 \\
\hline Parathyroid hormone (pg/mL) & $188.03 \pm 154.67$ & ND & $212.73 \pm 176.85$ & 0.27 \\
\hline ß2-microglobuline (mg/L) & $25.88 \pm 7.77$ & $22.96 \pm 5.57$ & $21.80 \pm 6.53$ & 0.00001 \\
\hline C-reactive protein (mg/L) & $14.59 \pm 27.10$ & $9.04 \pm 10.14$ & $11.81 \pm 30.60$ & 0.64 \\
\hline Serum albumin (g/L) & $35.07 \pm 4.52$ & $37.34 \pm 2.99$ & $40.02 \pm 4.58$ & 0.0002 \\
\hline \multicolumn{5}{|l|}{ Treatment } \\
\hline ESA ( $\mu \mathrm{g} / 28$ days) & $126.4 \pm 91.9$ & $109.63 \pm 101.03$ & $108.20 \pm 112.70$ & 0.07 \\
\hline Iron supplementation (mg/week) & $77.78 \pm 87.62$ & $15.56 \pm 42.40$ & $24.44 \pm 52.90$ & 0.0003 \\
\hline
\end{tabular}




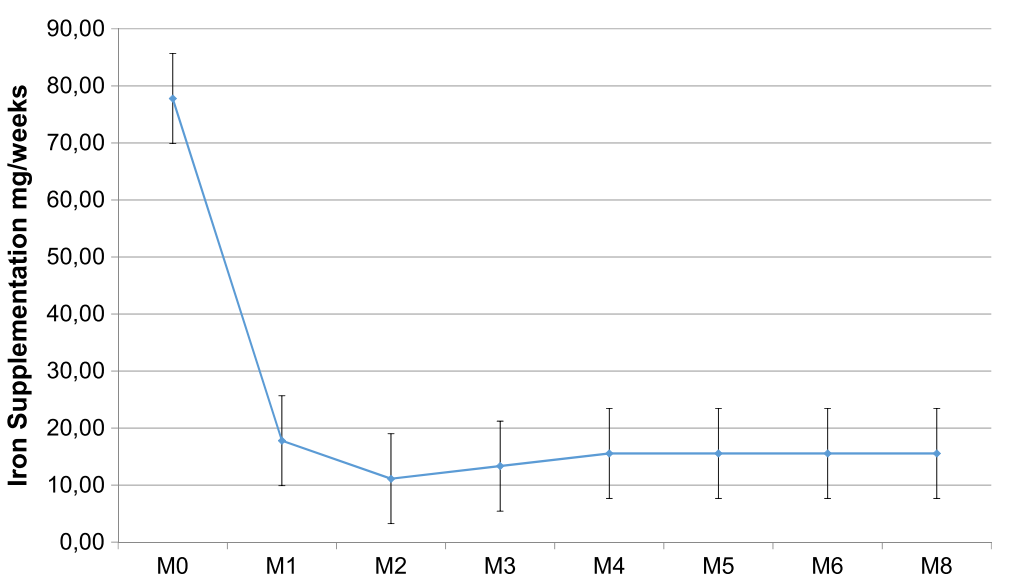

Fig. 3 Iron supplementation during the follow-up period

revised by Healthcare Institutions, but are still discussed. Although serum ferritine level and TSAT are traditional biomarkers of iron storage in patients with anemia, there are some concerns regarding their relevance [42, 43]. There are alternative indicators of iron metabolism, such as percentage of hypochromic red blood cells, reticulocyte hemoglobin content, soluble transferrin receptor and serum hepcidin. As these serum biomarkers are not routinely measured, we did not assess them in our study. However, it could be interesting to monitor them within the framework of a strategy for lowering IV iron supplementation.

Efficacy of different routes of administration in iron deficiency therapy was compared, and IV iron infusions seemed to be more efficient than oral iron in CKD patients, in both non dialysis $[44,45]$ and dialysis patients $[22,46]$. However, this should be weighed against some potential complications associated with IV iron infusions. The risk of hypersensitivity reactions during IV iron infusions have led the Health Authorities in Europe and in France to recommend new precautions for IV iron supplementation [37, 38]. In particular, IV iron medicines should only be administered in medical institutions with resuscitation facilities in France. In the light of these data, the current guidelines from the Health Societies and Pharmaceutical Manufacturers recommend that oral iron therapy may still be used as the first option in iron deficiency therapy, especially in nondialysis CKD patients, and IV iron infusion should only be considered in both patients experiencing intolerance and failure to respond to oral iron $[7,8]$. Our approach to lower IV iron supplementation should permit to limit the risk of anaphylaxis by reducing the frequency of infusions.

Several IV iron-containing medicines are currently available [40], and each formulation has its own usage instructions. In our unit, an iron saccharose complex is given intravenously at the weekly dose of 100 or $200 \mathrm{mg}$ as a single infusion during the midweek dialysis sessions. Clinical practices for the use of IV iron supplementation in dialysis differ in terms of drugs, dosing frequency, and amount, but at our knowledge, there is no register for all these practices. Results from a retrospective study comparing maintenance infusions of low iron doses to bolus administration of higher and less frequent doses suggested a correlation between the practice of bolus dosing and the risk of infection [30, 47]. More recently, a study was performed to focus on the highest iron amount infused per month without liver iron overload and suggested that the threshold dose should be $250 \mathrm{mg}$ monthly [48].

In our study, reduction in iron amount was more important in the first months of the follow-up (Fig. 2), illustrating a progressive utilization of iron stores in our patients. However, iron amount was significantly different at the beginning versus the end of the study and achieved a stable amount fivefold lower than the previous one used before the implementation of the new approach. The utilization of iron store observed in our study needs to be viewed against the absence of incident dialysis patients who are more likely to experience iron deficiency.

In addition, hemoglobin levels remained in the recommended therapeutic window. We have maintained the biochemical monitoring of our dialysis patients and did not show any compensatory increase of iron amount and ESA dose after a 1-year period.

Our study has some limitations related to the size of our dialysis unit. Our findings need therefore to be confirmed in larger studies including a comparison with a control group. However, our study is the first observational study suggesting that an approach to lower IV iron supplementation is applicable in dialysis settings without increasing ESA dosing and lowering hemoglobin levels. 


\section{Conclusion}

Iron plays a central role in the management of anemia of hemodialysis patients and may improve ESA responsiveness. It is widely used nowadays in daily practice in dialysis units, even when ferritin and TSAT levels are high. As IV iron supplementation can induce severe adverse effects, challenges faced by prescribing physicians are especially to achieve the lowest effective dose. Our study suggests that a strategy designed to lower IV iron supplementation can be applied in a wide range of dialysis units without lowering hemoglobin level or increasing ESA dosing in hemodialysis patients. Further prospective larger studies with a control group are needed to validate this approach in hemodialysis patients. Regarding current clinical practices, a moderate IV iron supplementation seems realistic in everyday clinical practice.

\section{Abbreviations}

CKD: Chronic kidney disease; CRP: C-reactive protein; DOPPS: Dialysis Outcomes and Practice Patterns Study; ESA: Erythropoiesis-stimulating agent; IV: Intravenous; LMWH: Low molecular weight heparin; PTH: Parathyroid hormone; SF: Serum ferritin; TSAT: Transferrin saturation

\section{Acknowledgements}

The authors thank Dr Manon Dekeyser, Dr Emmanuelle Laurain, Dr Alexandre Martin and Dr Pierre Filipozzi for overall care of patients and awareness of the conduct of the study. They are extremely grateful to the patients who contributed to the study and the paramedical staff of the dialysis unit at the University Hospital in Nancy.

\section{Funding}

No Funding.

\section{Availability of data and materials}

An excel file with anonymised data is available upon request to Dr Peters Nicolas Olivier (Department of Nephrology, University hospital, Vandoeuvre les Nancy, France, n.peters@chru-nancy.fr).

\section{Authors' contributions}

All authors (NP, NJ, JC, GR, LF) made substantial contributions to the conception and design of the study. NP and JC were responsible of data collection. NJ performed data analyses. NP produced the tables and graphs. The manuscript was prepared by NP and was then circulated repeatedly among LF and GR for critical revision. All authors (NP, NJ, JC, GR, LF) assisted with interpretation of data and gave their final approval regarding submission for publication. All authors read and approved the final manuscript.

\section{Competing interests}

The authors declare that they have no competing interests.

\section{Consent for publication}

Not applicable.

\section{Ethics approval and consent to participate}

In accordance with French law, no ethics committee's oversight was required as the design of the study was strictly observational [49]. The changes in our IV iron supplementation practices implemented in February 2014 in our dialysis unit were consistent with current nephrology practices. All patients were given verbal information about the study and gave verbal consent to participate in the study according to the French law for observational study [49].

\section{Publisher's Note}

Springer Nature remains neutral with regard to jurisdictional claims in published maps and institutional affiliations.

\section{Author details}

${ }^{1}$ Department of Nephrology, University hospital, Vandoeuvre les Nancy, France. ${ }^{2}$ Department of Medical Informatics, University hospital, Vandoeuvre les Nancy, France. ${ }^{3}$ Orpailleur, LORIA UMR 7503, Vandoeuvre les Nancy, France. ${ }^{4}$ Department of Nephrology and Dialysis, Claude Galien Hospital of the Ramsay Générale de Santé, Quincy-sous-Senart, France.

Received: 26 November 2016 Accepted: 15 March 2017

Published online: 20 March 2017

\section{References}

1. Jones M, Ibels L, Schenkel B, Zagari M. Impact of epoetin alfa on clinical end points in patients with chronic renal failure: a meta-analysis. Kidney Int. 2004:65:757-67.

2. Levin A. Anemia and left ventricular hypertrophy in chronic kidney disease populations: a review of the current state of knowledge. Kidney Int. 2002;80:S35-8

3. Collins AJ, Li S, St Peter W, Ebben J, Roberts T, Ma JZ, Manning W. Death, hospitalization, and economic associations among incident hemodialysis patients with hematocrit values of 36 to 39\%. J Am Soc Nephrol. 2001;12:2465-73.

4. Brookhart MA, Schneeweiss S, Avorn J, Bradbury BD, Liu J, Winkelmayer WC Comparative mortality risk of anemia management practices in incident hemodialysis patients. JAMA. 2010;303:857-64

5. Besarab A, Bolton WK, Browne JK, Egrie JC, Nissenson AR, Okamoto DM, Schwab SJ, Goodkin DA. The effects of normal as compared with low hematocrit values in patients with cardiac disease who are receiving hemodialysis and epoetin. N Engl J Med. 1998;339:584-90.

6. Singh AK, Szczech L, Tang KL, Barnhart H, Sapp S, Wolfson M, Reddan D, Investigators CHOIR. Correction of anemia with epoetin alfa in chronic kidney disease. N Engl J Med. 2006;355:2085-98.

7. Kidney Disease: Improving Global Outcomes (KDIGO) Anemia Work Group. KDIGO Clinical Practice Guideline for Anemia in Chronic Kidney Disease. Kidney Int. 2012;2:S279-335.

8. Locatelli F, Bárány P, Covic A, De Francisco A, Del Vecchio L, Goldsmith D, Hörl W, London G, Vanholder R, Van Biesen W, ERA-EDTA ERBP Advisory Board. Kidney Disease: Improving Global Outcomes guidelines on anaemia management in chronic kidney disease: a European Renal Best Practice position statement. Nephrol Dial Transplant. 2013;28:1346-59.

9. Kliger AS, Foley RN, Goldfarb DS, Goldstein SL, Johansen K, Singh A, Szczech L. KDOQI US commentary on the 2012 KDIGO Clinical Practice Guideline for Anemia in CKD. Am J Kidney Dis. 2013:62:849-59.

10. Moist LM, Troyanov S, White CT, Wazny LD, Wilson JA, McFarlane $P$, Harwood L, Sood MM, Soroka SD, Bass A, Manns BJ. Canadian Society of Nephrology commentary on the 2012 KDIGO Clinical Practice Guideline for Anemia in CKD. Am J Kidney Dis. 2013;62:860-73.

11. Tsubakihara $Y$, Nishi S, Akiba T, Hirakata H, Iseki K, Kubota M, Kuriyama S, Komatsu Y, Suzuki M, Nakai S, Hattori M, Babazono T, Hiramatsu M, Yamamoto H, Bessho M, Akizawa T. 2008 Japanese Society for Dialysis Therapy: guidelines for renal anemia in chronic kidney disease. Ther Apher Dial. 2010;14:240-75.

12. National Institute for Health and Care Excellence (Nice). Anaemia Management in Chronic Kidney Disease. London: NICE; 2015. Available from https://www.nice.org.uk/guidance/ng8/evidence/full-guideline-70545133. Accessed 17 Mar 2017

13. Locatelli F, Nissenson AR, Barrett BJ, Walker RG, Wheeler DC, Eckardt KU, Lameire NH, Eknoyan G. Clinical practice guidelines for anemia in chronic kidney disease: problems and solutions. A position statement from Kidney Disease: Improving Global Outcomes (KDIGO). Kidney Int. 2008;74:1237-40.

14. Locatelli F, Covic A, Eckardt KU, Wiecek A, Vanholder R, ERA-EDTA ERBP Advisory Board. Anaemia management in patients with chronic kidney disease: a position statement by the Anaemia Working Group of European Renal Best Practice (ERBP). Nephrol Dial Transplant. 2009;24:348-54.

15. Madore F, White CT, Foley RN, Barrett BJ, Moist LM, Klarenbach SW, Culleton BF, Tonelli M, Manns BJ, Canadian Society of Nephrology. Clinical practice guidelines for assessment and management of iron deficiency. Kidney Int. 2008;110:57-11. 
16. Rottembourg J, Rostoker G. Use of Iron Therapy in Chronic Kidney Disease. Arch Clin Nephrol. 2016;1:12-4.

17. Charytan DM, Barton Pai A, Chan CT, Coyne DW, Hung AM, Kovesdy CP, Fishbane S. Considerations and Challenges in Defining Optimal Iron Utilization in Hemodialysis. J Am Soc Nephrol. 2015;26:1238-47.

18. Freburger JK, Ng LJ, Bradbury BD, Kshirsagar AV, Brookhart MA. Changing patterns of anemia management in US hemodialysis patients. Am J Med. 2012;125:906-14.

19. Bailie GR, Larkina M, Goodkin DA, Li Y, Pisoni RL, Bieber B, Mason N, Tong L, Locatelli F, Marshall MR, Inaba M, Robinson BM. Variation in intravenous iron use internationally and over time: the Dialysis Outcomes and Practice Patterns Study (DOPPS). Nephrol Dial Transplant. 2013;28:2570-9.

20. Macdougall IC, Bock AH, Carrera F, Eckardt KU, Gaillard C, Van Wyck D, Roubert B, Nolen JG, Roger SD, on behalf of the FIND-CKD Study Investigators. FIND-CKD: a randomized trial of intravenous ferric carboxymaltose versus oral iron in patients with chronic kidney disease and iron deficiency anaemia. Nephrol Dial Transplant. 2014;29:2075-84.

21. Macdougall IC, Bock A, Carrera F, Eckardt KU, Gaillard C, Van Wyck D, Roubert B, Cushway T, Roger SD, FIND-CKD Study Investigators. The FINDCKD study a randomized controlled trial of intravenous iron versus oral iron in non-dialysis chronic kidney disease patients: background and rationale. Nephrol Dial Transplant. 2014;29:843-50

22. Coyne DW, Kapoian T, Suki W, Singh AK, Moran JE, Dahl NV, Rizkala AR, DRIVE Study Group. Ferric gluconate is highly efficacious in anemic hemodialysis patients with high serum ferritin and low transferrin saturation: results of the Dialysis Patients Response to IV Iron with Elevated Ferritin (DRIVE) Study. J Am Soc Nephrol. 2007;18:975-84.

23. Besarab A, Amin N, Ahsan M, Vogel SE, Zazuwa G, Frinak S, Zazra JJ, Anandan JV, Gupta A. Optimization of epoetin therapy with intravenous iron therapy in hemodialysis patients. J Am Soc Nephrol. 2000;11:530-8.

24. Mitka M. New findings challenge thinking about anemia, iron deficiency, and heart risk. JAMA. 2010;303:405-6.

25. Anker SD, Comin Colet J, Filippatos G, Willenheimer R, Dickstein K, Drexler H, Lüscher TF, Bart B, Banasiak W, Niegowska J, Kirwan BA, Mori C, von Eisenhart RB, Pocock SJ, Poole-Wilson PA, Ponikowski P, FAIR-HF Trial Investigators. Ferric carboxymaltose in patients with heart failure and iron deficiency. N Engl J Med. 2009;361:2436-48.

26. Zacharski LR, Chow BK, Howes PS, Shamayeva G, Baron JA, Dalman RL, Malenka DJ, Ozaki CK, Lavori PW. Reduction of iron stores and cardiovascular outcomes in patients with peripheral arterial disease: a randomized controlled trial. JAMA. 2007;297:603-10.

27. Bailie GR, Larkina M, Goodkin DA, Li Y, Pisoni RL, Bieber B, Mason N, Tong L, Locatelli F, Marshall MR, Inaba M, Robinson BM. Data from the Dialysis Outcomes and Practice Patterns Study validate an association between high intravenous iron doses and mortality. Kidney Int. 2015;87:162-8.

28. Agarwal R, Kusek JW, Pappas MK. A randomized trial of intravenous and oral iron in chronic kidney disease. Kidney Int. 2015;88:905-14.

29. Kuragano T, Matsumura O, Matsuda A, Hara T, Kiyomoto H, Murata T, Kitamura K, Fujimoto S, Hase H, Joki N, Fukatsu A, Inoue T, Itakura I, Nakanishi T. Association between hemoglobin variability, serum ferritin levels, and adverse events/mortality in maintenance hemodialysis patients. Kidney Int. 2014;86:845-54.

30. Brookhart MA, Freburger JK, Ellis AR, Wang L, Winkelmayer WC, Kshirsagar $A V$. Infection risk with bolus versus maintenance iron supplementation in hemodialysis patients. J Am Soc Nephrol. 2013;24:1151-8.

31. Afzali B, Goldsmith DJ. Long-term risks of increased use of intravenous iron. Lancet. 2007;370:482.

32. Sullivan JL. Long-term risks of increased use of intravenous iron. Lancet. 2007;370:481-2

33. Rostoker G, Griuncelli M, Loridon C, Couprie R, Benmaadi A, Bounhiol C, Roy M, Machado G, Janklewicz P, Drahi G, Dahan H, Cohen Y. Hemodialysisassociated hemosiderosis in the era of erythropoiesis-stimulating agents: a MRI study. Am J Med. 2012;125:991-9.

34. Rostoker G, Cohen Y. Magnetic Resonance Imaging Repercussions of Intravenous Iron Products Used for Iron-Deficiency Anemia and DialysisAssociated Anemia. J Comput Assist Tomogr. 2014;38:843-4.

35. Wysowski D, Swartz L, Borders-Hemphill V, Goulding MR, Dormitzer C. Use of parenteral iron products and serious anaphylactic-type reactions. Am J Hematol. 2010;85:650-4.

36. Rampton D, Folkersen J, Fishbane S, Hedenus M, Howaldt S, Locatelli F, Patni S, Szebeni J, Weiss G. Hypersensitivity reactions to intravenous iron: guidance for risk minimization and management. Haematologica. 2014:99:1671-6.

37. New recommendations to manage risk of allergic reactions with intravenous iron-containing medicines. Available on http://www.ema. europa.eu/docs/en_GB/document_library/Referrals_document/IV_iron_31/ WC500151308.pdf. Accessed 17 Mar 2017.

38. INSTRUCTION NoDGOS/PF2/R3/DGS/PP2/2014/32 du 24 janvier 2014 relative aux modalités d'utilisation des spécialités à base de fer injectable. Ministère des Affaires sociales et de la Santé. Available on http://circulaire.legifrance. gouv.fr/pdf/2014/01/cir_37878.pdf. Accessed 17 Mar 2017.

39. Rostoker G, Hummel A, Chantrel F, Ryckelynck JP. Therapy of anemia and iron deficiency in dialysis patients: an update. Nephrol Ther. 2014;10:221-7. French.

40. Rottembourg J, Rostoker G. Use of intravenous iron supplementation in chronic kidney disease: Interests, limits, and recommendations for a better practice. Nephrol Ther. 2015;11:531-42. French.

41. Del Vecchio L, Longhi S, Locatelli F. Safety concerns about intravenous iron therapy in patients with chronic kidney disease. Clin Kidney J. doi: 10.1093/ ckj/sfv142First published online: January 6, 2016

42. Kalantar-Zadeh K, Kalantar-Zadeh K, Lee GH. The fascinating but deceptive ferritin: to measure it or not to measure it in chronic kidney disease? Clin J Am Soc Nephrol. 2006;1:S9-18.

43. Rostoker G, Griuncelli M, Loridon C, Magna T, Machado G, Drahi G, et al. Reassessment of Iron Biomarkers for Prediction of Dialysis Iron Overload: An MRI Study. PLoS ONE. 2015;10:e0132006. doi:10.1371/journal.pone.0132006.

44. Qunibi WY, Martinez C, Smith M, Benjamin J, Mangione A, Roger SD. A randomized controlled trial comparing intravenous ferric carboxymaltose with oral iron for treatment of iron deficiency anaemia of non-dialysisdependent chronic kidney disease patients. Nephrol Dial Transplant. 2011;26:1599-607.

45. Van Wyck DB, Roppolo M, Martinez CO, Mazey RM, McMurray S, United States Iron Sucrose (Venofer) Clinical Trials Group. A randomized, controlled trial comparing IV iron sucrose to oral iron in anemic patients with nondialysis-dependent CKD. Kidney Int. 2005;68:2846-56.

46. Rozen-Zvi B, Gafter-Gvili A, Paul M, Leibovici L, Shpilberg O, Gafter U. Intravenous versus oral iron supplementation for the treatment of anemia in CKD: systematic review and meta-analysis. Am J Kidney Dis. 2008:52:897-906.

47. Rhee CM, Kalantar-Zadeh K. Is iron maintenance therapy better than load and hold? J Am Soc Nephrol. 2013;24:1028-31.

48. Rostoker G, Griuncelli M, Loridon C, Magna T, Janklewicz P, et al. Maximal standard dose of parenteral iron for hemodialysis patients: an MRI-based decision tree learning analysis. PLoS ONE. 2014;9: e115096. doi:10.1371/ journal.pone.0115096.

49. Claudot F, Alla F, Fresson J, Calvez T, Coudane H, Bonaiiti-Pellié C. Ethics and observational studies in medical research: various rules in a common framework. Int J Epidemiol. 2009:38:1104-8.

\section{Submit your next manuscript to BioMed Central and we will help you at every step:}

- We accept pre-submission inquiries

- Our selector tool helps you to find the most relevant journal

- We provide round the clock customer support

- Convenient online submission

- Thorough peer review

- Inclusion in PubMed and all major indexing services

- Maximum visibility for your research

Submit your manuscript at www.biomedcentral.com/submit
) Biomed Central 